\title{
QUALIDADE DA ÁGUA NA BACIA HIDROGRÁFICA DO RIBEIRÃO AREADO ALTO FRANCISCO, ESTADO DE MINAS GERAIS EM ÁREA DE OCORRÊNCIA DE TUFITO E DIFERENTES TIPOS SOLOS
}

\author{
Juberto Babilônia de Sousa \\ Professor no Instituto Federal de Educação, Ciência e Tecnologia de Mato Grosso \\ Campus Cáceres/IFMT, Cáceres - MT, Brasil \\ jubertobabilonia@yahoo.com.br
}

Flávio Rodrigues do Nascimento Professor do Departamento de Geografia, Centro de Ciências, Universidade Federal do Ceará Universidade Federal do Ceará. Fortaleza - CE, Brasil flaviogeo@bol.com.br

Célia Alves de Souza

Professora Adjunto do Departamento de Geografia da Universidade do Estado de Mato Grosso Cáceres - MT, Brasil celiaalvesgeo@globo.com

\begin{abstract}
RESUMO
Este estudo foi realizado na bacia hidrográfica do Ribeirão Areado $\left(440,90 \mathrm{~km}^{2}\right)$, no Alto Francisco no Estado de Minas Gerais. O objetivo do estudo foi avaliar qualidade das águas superficiais da bacia do Ribeirão Areado sob influência direta e indireta de tufos vulcânicos. Amostras de água foram coletadas para determinar a suas qualidades químicas, sendo quinze pontos distribuídos em rios, córregos, represas e nascentes, nos períodos seco e chuvoso. Os resultados apontaram que a composição química da água apresentou-se comportamento diferenciado nos dois períodos de coleta. Houve uma tendência de maior concentração de elementos químico no período seco do ano, notadamente para os elementos $\mathrm{Co}, \mathrm{Pb}, \mathrm{B}, \mathrm{V}, \mathrm{Cu}, \mathrm{Ni}, \mathrm{Cr}, \mathrm{Cd}, \mathrm{Ca}, \mathrm{P}, \mathrm{Ti}, \mathrm{Mg}$ e Mn. Para os elementos $\mathrm{Zn}, \mathrm{Fe}, \mathrm{K}, \mathrm{Al}$ e $\mathrm{Na}$ a maior média foi apresentada para o período chuvoso. A concentração dos elementos químicos na água $\mathrm{Zn}, \mathrm{Pb}, \mathrm{Cu}, \mathrm{Ni}, \mathrm{Cr}, \mathrm{Fe}, \mathrm{P}, \mathrm{Mn}$ e $\mathrm{Al}$, foram considerado acima dos valores considerados normais pela legislação brasileira CONAMA, inclusive não se enquadrando nos padrões de potabilidade destacando-se com valores acima os elementos $\mathrm{Cd}, \mathrm{Cr}, \mathrm{Pb}, \mathrm{Fe}, \mathrm{Al}$ e $\mathrm{Mn}$ no período chuvoso e os elementos $\mathrm{Pb}$, Fe e Al no período seco.
\end{abstract}

Palavras-chave: Elementos químicos. Águas superficiais. Contaminação.

\section{QUALITY OF THE WATER IN THE HYDROGRAPHIC BASIN OF THE RIBEIRÃO AREADO, UPPER FRANCISCO RIVER, STATE OF MINAS GERAIS IN AREA OF OCCURRENCE OF TUFITO}

\begin{abstract}
This study was carried out in the watershed of the River Areado (440.90 km2)/Alto Francisco, state of Minas Gerais. The objective of the study was to evaluate the quality of the surface waters of the Ribeirao Areado basin under direct and indirect influence of volcanic tuffs. Water samples were collected to determine their chemical quality, as fifteen points were distributed in rivers, streams, reservoirs and fountains, during dry and rainy periods. The results showed that the chemical composition of the water presented different behavior in the two collection periods. There was a trend of higher concentration of chemical elements in the dry period of the year, especially for the elements $\mathrm{Co}, \mathrm{Pb}, \mathrm{B}, \mathrm{V}, \mathrm{Cu}, \mathrm{Ni}, \mathrm{Cr}, \mathrm{Cd}, \mathrm{Ca}, \mathrm{P}, \mathrm{Ti}, \mathrm{Mg}$ and $\mathrm{Mn}$. For the elements $\mathrm{Zn}, \mathrm{Fe}$, $\mathrm{K}, \mathrm{Al}$ and $\mathrm{Na}$ the highest average was presented for the rainy season. The concentration of the chemical elements in the water $\mathrm{Zn}, \mathrm{Pb}, \mathrm{Cu}, \mathrm{Ni}, \mathrm{Cr}, \mathrm{Fe}, \mathrm{P}, \mathrm{Mn}$ and $\mathrm{Al}$, were considered above the values considered normal by the Brazilian legislation CONAMA, including not meeting the standards of potability, highlighting values above the elements $\mathrm{Cd}, \mathrm{Cr}, \mathrm{Pb}, \mathrm{Fe}, \mathrm{Al}$ and $\mathrm{Mn}$ in the rainy season and the elements $\mathrm{Pb}, \mathrm{Fe}$ and $\mathrm{Al}$ in the dry period.
\end{abstract}

Key words: Chemical elements. Surface waters. Contamination

$\begin{array}{llllll}\text { Caminhos de Geografia } & \text { Uberlândia - MG } & \text { v. 19, n. } 68 & \text { Dez/2018 } & \text { p. 81-100 } & \text { Página } 101\end{array}$




\section{INTRODUÇÃO}

O estudo trata-se da análise da composição química em águas de rios, córregos, nascentes e represas na bacia hidrografica do Ribeirão Areado. Adota-se a bacia hidrográfica como unidade de análise, por considerar uma unidade importante para estudos ambientais (ROSS e DEL PRETTE, 1998). Trata-se de uma unidade integradora das atividades humanas com o meio físico-natural (NASCIMENTO e CUNHA, 2006).

A água é um elemento natural de múltiplas finalidades, importante para o consumo humano (com funções vitais da água no corpo humano, contribuindo nas reações químicas, no controle da temperatura do corpo e no transporte de nutrientes), aos animais e para manutenção dos ecossistemas (TUNDISI e MATSUMURA-TUNDISI, 2011). No ambiente a água adquire, dentre outras funções, de ser o principal meio de dispersão e recepção de elementos químicos entre as paisagens, que denominamos de compartimentos morfopedológicos. Essa dispersão e recepção ocorrem em sentido superficial ou subsuperficial do terreno e na forma solúvel ou adsorvida nos sedimentos em suspensão e, seu nível de concentração, determinará a qualidade da água para os usos diversos.

A qualidade das águas naturais, bem como daquela fornecida ao consumidor, depende das características químicas, físicas e biológicas (AZEVEDO NETTO, 1987). Sua qualidade pode ser definida a partir desses parâmetros e, sobretudo, vai depender da sua composição química. Os teores de elementos químicos, benéficos e/ou tóxicos presentes na água é que definirá a sua qualidade para o consumo humano, animal e seu lançamento ao meio ambiente (VALENTE e CASTRO, 1981).

A qualidade das águas naturais, bem como daquela fornecida ao consumidor, depende das características químicas, físicas e biológicas (AZEVEDO NETTO, 1987). Sua qualidade pode ser definida a partir desses parâmetros e, sobretudo, vai depender da sua composição química. Os teores de elementos químicos, benéficos e/ou tóxicos presentes na água é que definirá a sua qualidade para o consumo humano (os padrões estabelecido pelo CONAMA), animal e seu lançamento ao meio ambiente (VALENTE e CASTRO, 1981).

A qualidade é determinada confrontando os dados analíticos com padrões pré-estabelecidos e, quando, apresentar concentração de determinado elemento químico acima dos padrões em condições naturais é considerada contaminada (VALENTE e CASTRO, 1981). A concentração dos elementos químicos nas águas é determinada pelo grau de intemperismo e pela litologia original. As atividades humanas desenvolvidas na bacia pode alterar a composição química da água.

Assim sendo, a composição das águas naturais superficiais e subsuperficiais são determinadas diretamente pelos teores de elementos químicos que podem estar presentes no meio. Deste modo, podem estar presentes tanto em razão de processos naturais quanto devido à atividade humanas (KABATA-PENDIAS e PENDIAS, 2001). Ainda segundo os mesmos autores, os processos naturais que contribuem para o aparecimento de elementos químicos na água são 0 intemperismo de rochas e a lixiviação de elementos no perfil do solo, enquanto que as fontes antropogênicas estão associadas principalmente com as atividades industriais, mineração e agropecuárias.

O tufito é uma rocha com diferentes proporções de material piroclástico, química e mineralogicamente considerada máfica que, devido a suas características estruturais proporciona ampla frente de penetração de água (RESENDE et. al., 1988). Essa condição permite que haja intemperização e lixiviações (RESENDE et. al., 1988). Os minerais e rochas máficos decompõem com facilidade em contato com a água. Contudo, as atividades antrópicas figuram no rol das mais importantes emissões através das atividades industriais, mineração, efluentes domésticos, águas superficiais provenientes de áreas cultivadas com adubos químicos e principalmente, daquelas onde são usados defensivos agrícolas (OLIVEIRA e MARINS, 2011).

Os elementos químicos, principalmente os elementos traços, em grande concentração, merecem maior preocupação, principalmente por serem não degradáveis, permanecendo por longos períodos no ambiente, especialmente nos sedimentos em suspensão (KABATA-PENDIAS e PENDIAS, 2001). Segundo Cotta et. al. (2006), nos últimos anos, tem aumentado a investigação sobre metais presentes em sedimentos, não mais como um reservatório ou ambiente de deposição de espécies químicas, mas como um compartimento aquático ativo que desempenha

$\begin{array}{llllll}\text { Caminhos de Geografia } & \text { Uberlândia - MG } & \text { v. 19, n. 68 } & \text { Dez/2018 } & \text { p. 81-115 Página } 102\end{array}$


um papel fundamental na redistribuição dessas espécies no meio aquático e, que, portanto, entre as paisagens.

Os fenômenos de acúmulo e de redisposição de espécies nos sedimentos em suspensão os qualificam como de extrema importância em estudos de impacto ambiental, pois registram em caráter mais permanente os efeitos de contaminação (MOZETO, 1996). Assim sendo, a determinação de elementos traço em sedimentos de suspensão permite detectar o grau de contaminação a que estão sujeitos a água e, bem como, os compartimentos naturais por onde ela transita. Tornando possível estabelecer concentração que ocorra risco de efeito adverso à saúde humana. As águas contaminadas relacionadas aos tipos de rochas, frequentemente são salobras e apresentam dureza (quantidade de sais e carbonatos) elevada.

O material em suspensão será considerado contaminado quando os valores médios dos elementos-traços ultrapassarem os valores considerados normais para os solos (VN) e acima da média mundial (MM) (MARTIN e MEYBECK, 1979). Os materiais em suspensão deste estudo são oriundos da deposição de partículas primárias do solo provenientes dos processos erosivos do entorno dos cursos de água e o do intemperismo das rochas e, que, portanto, guardam estreita relação com os materiais de origem contidos na Bacia e processos pedogenéticos atuantes e solos da bacia.

A análise busca associar a funcionalidade química (a função dos contribuintes químicos), das paisagens (rochas, solos, água e uso da terra) e suas interações que se apresentam ligada entre si por migração de elementos químicos. Nesse sentido, busca-se a partir da qualidade química das águas superficiais e subsuperficiais identificarem as áreas fontes de elementos químicos para os corpos d'água e a partir da sua constituição química indicar os seus mais diversos tipos de usos.

O objetivo do estudo foi avaliar qualidade das águas superficiais da bacia do Ribeirão Areado sob influência de tufos vulcânicos, comparando aos padrões de potabilidade (portaria no 1.669/2000) e com os valores padrões do CONAMA (resolução no 357/2005), considerando os usos múltiplos dos recursos hídricos.

\section{MATERIAL E MÉTODOS}

\section{Area de estudo}

Este estudo foi realizado na bacia hidrográfica do ribeirão Areado $\left(440,90 \mathrm{~km}^{2}\right)$ que está inserida na porção oeste do alto curso da bacia hidrográfica do rio São Francisco, Estado de Minas Gerais, entre as coordenadas geográficas de $18^{\circ} 30^{\prime}$ a $19^{\circ} 37^{\prime}$ de latitude Sul e $46^{\circ} 20^{\prime}$ a $46^{\circ}$ e 50 ' de longitude Oeste de Greenwich (figura 1) e, representa 0,07\% da área total da bacia do rio do São Francisco.

A Bacia é composta por rios e córregos de médio e pequeno porte. Como rios principais destacam-se o São Bento e o Areado, com drenagem predominante do tipo meandrante e irregular. Compreende setores limítrofes do sul do município de Patos de Minas, norte do município de Carmo Paranaíba, leste do município de Tiros e oeste do município de Lagoa Formosa. 
Figura 1: Bacia do ribeirão Areado/Alto Francisco - MG. Fonte: Adaptado a partir da carta topográfica Carmo Paranaíba na escala 1:100.000 do ministério do exército - DSG.

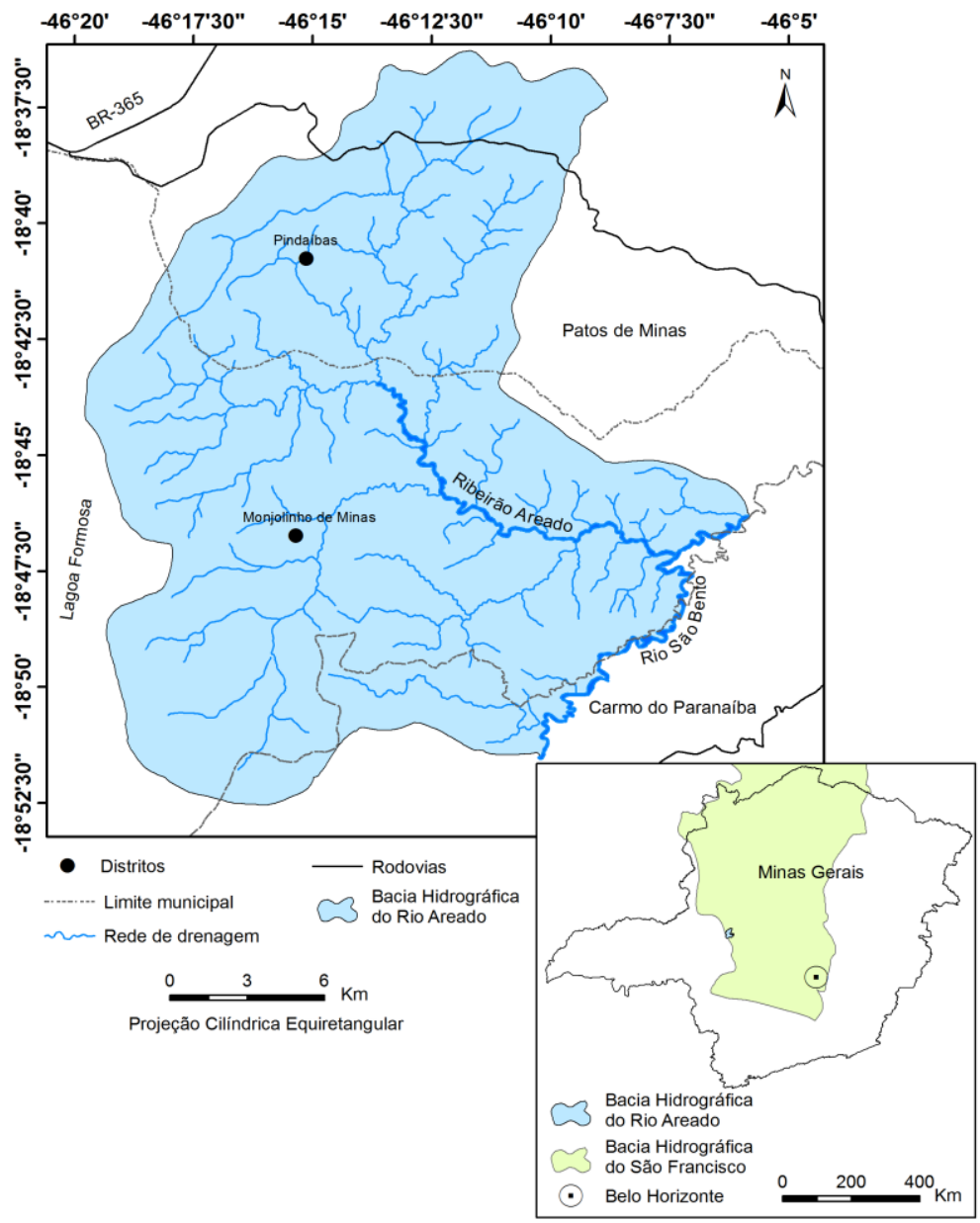

Elaboração: os autores.

\section{Procedimentos metodológicos}

As amostras foram coletadas no período de estiagem e no período chuvoso, com coleta de quinze amostras de água em diferentes pontos, sendo quatro em nascentes, sete em córregos e cinco em rios ao longo da região. A escolha de dois períodos (seco e chuvoso) se deu com intuito de verificar a sazonalidade da qualidade química da água. A escolha dos pontos de amostragem considerou a hidrografia, geologia e solo e tipo de uso do solo do entorno, dando ênfase a geologia pelo fato da possibilidade dos elementos analisados serem herdados da rocha ou do solo.

A coleta das amostras foi feita manualmente, utilizando-se frascos de polietileno (garrafas pet) com capacidade de $500 \mathrm{~mL}$ previamente descontaminadas no laboratório utilizando-se de solução de ácido nítrico comercial ou ácido clorídrico a 10\% (v/v) e água deionizada.

Todos os frascos utilizados na coleta das amostras destinadas às análises de todos os pontos amostrados foram enxaguados três vezes com água do próprio local de coleta, antes da amostragem. As amostras foram coletadas a cerca de $10 \mathrm{~cm}$ abaixo da superfície da água. Os frascos foram identificados, especificando o ponto de coleta.

As medidas de $\mathrm{pH}$ e condutividade elétrica nas amostras de água foram feitas no próprio local de amostragem utilizando-se de um medidor portátil de $\mathrm{pH}$ e condutividade elétrica. As determinações foram realizadas mediante a introdução dos eletrodos, em copos de polietileno, de pequeno volume de água a ser analisada (cerca de $50 \mathrm{~mL}$ ). As determinações foram feitas no mesmo volume de água, com o mostrador digital indicando o parâmetro a ser medido. Em etapa anterior às determinações, foi

$\begin{array}{llllll}\text { Caminhos de Geografia } & \text { Uberlândia - MG } & \text { v. 19, n. 68 } & \text { Dez/2018 } & \text { p. 81-115 } & \text { Página } 104\end{array}$


realizada a calibração do aparelho utilizando para as medidas de $\mathrm{pH}$ soluções-padrão de $\mathrm{pH} 4,0$ e 7,0 e, para a condutividade elétrica, solução de $\mathrm{KCl}_{0,01} \mathrm{~mol} \mathrm{~L}^{-1}$ (com condutividade padrão de $1413 \mathrm{mS} \mathrm{cm}^{-1}$ ).

As amostras de água foram transportadas até o laboratório em caixas de isopor sem preservação com agente químico, analisada em triplicata o mais rápido possível (APHA, 1998). Os reagentes utilizados nas análises foram de grau analítico, da marca VETEC ou equivalente. Foram feitos ensaios em branco para verificar qualquer contaminação.

A determinação da concentração de metais solúveis de $\mathrm{Zn}, \mathrm{Pb}, \mathrm{Cr}, \mathrm{Co}, \mathrm{V}, \mathrm{Cd}, \mathrm{Mn}, \mathrm{Cu}, \mathrm{Ni}, \mathrm{B}, \mathrm{Fe}$, $\mathrm{P}, \mathrm{Al}$ e $\mathrm{Na}$ foi adaptada do procedimento descrito no Standard methods for the examination of water and wastewater (APHA, 1998). Para isso, foram transferidos $100 \mathrm{~mL}$ de amostra de água filtrada em papel-filtro quantitativo da marca QUANTY JP, $\mathrm{n}^{\circ} 41$ para helermayer $250 \mathrm{~mL}$. Adiciona $10 \mathrm{~mL}$ de mistura ácida $1: 1(\mathrm{v} / \mathrm{v})$ dos ácidos nítrico $(65 \%, \mathrm{~m} / \mathrm{v})$ e perclórico $(72 \%, \mathrm{~m} / \mathrm{v})$, aquecendo-se, em seguida, em chapa aquecedora a $150{ }^{\circ} \mathrm{C}$ até quase a secura. Adicionam-se mais $10 \mathrm{~mL}$ da mistura ácida, aquecendo novamente até quase a secura.

Após a filtração do conteúdo dos helermayer em papel-filtro rápido da marca QUANTY JP, $n^{\circ} 41$, os filtrados foram recolhidos em balões volumétricos de $25 \mathrm{~mL}$, sendo o volume destes aferidos com solução de ácido nítrico a $1 \%(\mathrm{v} / \mathrm{v})$. Deste modo, a amostra foi pré-concentrada em quatro vezes. As concentrações dos metais nas soluções foram, então, determinadas em espectrofotômetro de absorção atômica (ICP-EOS), para Zn, Pb, Cr, Co, V, Cd, Mn, Cu, Ni, B, Fe e Al, enquanto para os demais elementos $\mathrm{P}$ e $\mathrm{Na}$ a fotometria de chamas.

Para determinação da concentração de elementos traços no material em suspensão foi utilizado a digestão em forno de microondas. O material em suspensão utilizado foi o do período chuvoso e obtido por filtração das amostras utilizando-se papel-filtro quantitativo da marca QUANTY JP, $n^{\circ}$ 41. Após a filtração, os filtros contendo o material em suspensão foram lavados com jatos de água deionizada para retirada do material em suspensão aderido as membranas filtrantes. $O$ excesso de água foi seco em estufa a $60^{\circ} \mathrm{C}$, até quase a secura.

Com a finalidade de digestão, amostras de aproximadamente $0,2000 \mathrm{~g}$ de material de suspensão (triturada até o tamanho de $2 \mathrm{~mm}$ ) foram transferidas para tubos de digestão apropriados, adicionando-se, $6 \mathrm{~mL}$ de $\mathrm{HNO}_{3}(65 \%, \mathrm{~m} / \mathrm{v}), 1 \mathrm{~mL}$ de $\mathrm{H}_{2} \mathrm{O}_{2}(30 \%$, v/v) e $4 \mathrm{~mL}$ de $\mathrm{HF}(40 \%, \mathrm{~m} / \mathrm{v})$. Após esta etapa, os tubos foram transferidos para o forno de microondas, sendo então feita à digestão. Em seguida, foi realizada a filtração em papel de filtro $n^{\circ} 41$ da marca QUANTY JP. Os filtrados foram recolhidos em balões volumétricos de $25 \mathrm{~mL}$, sendo os volumes dos balões aferidos com solução de ácido nítrico a $1 \%(\mathrm{v} / \mathrm{v})$. Foram feitas, então, determinações em espectrofotômetro de absorção atômica (ICP-EOS), para Zn, Pb, Cr, Co, V, Cd, Mn, Cu, Ni, B, Fe e $\mathrm{Al}$, enquanto para os demais elementos $\mathrm{P}$ e $\mathrm{Na}$ utilizou a fotometria de chamas.

Por fim, a dureza das amostras de água foi determinada pela fórmula: Dureza $\left(\mathrm{CaCO}_{3} \mathrm{mg} \mathrm{L}^{-1}\right)=$ $2,497\left[\mathrm{Ca} \mathrm{mg} \mathrm{L}{ }^{-1}\right]+4,118\left[\mathrm{Mg} \mathrm{mg} \mathrm{L}^{-1}\right]$ descrita no Standard methods for the examination of water and wastewater (APHA, 1998), em que as concentrações de cálcio e magnésio foram determinadas por espectrofotometria de absorção atômica.

\section{RESULTADOS E DISCUSSÃO}

A composição química da água na bacia hidrográfica do Ribeirão Areado pode estar diretamente relacionada a trecho percorrido pelo fluxo, seja, na superfície do solo ou nas fraturas das rochas que afloram. Assim, sua constituição química depende da riqueza química dos minerais e rochas e de fatores pedogenéticos. Este estudo enfatizou a influencia da geologia local pela possibilidade dos elementos químicos analisados serem herdados dos Grupos Geológicos Areado, Bambuí e Mata da Corda, com ênfase no último, por considerar a rocha tufito a principal fonte de elementos traços ao meio ambiente (figura 2). 
Figura 2: Pontos de coleta de água de drenagem para o estudo e sua relação com a geologia da Bacia. Elaborado a partir da carta topográfica Carmo Paranaíba na escala 1:100.000 do ministério do exército - DSG.

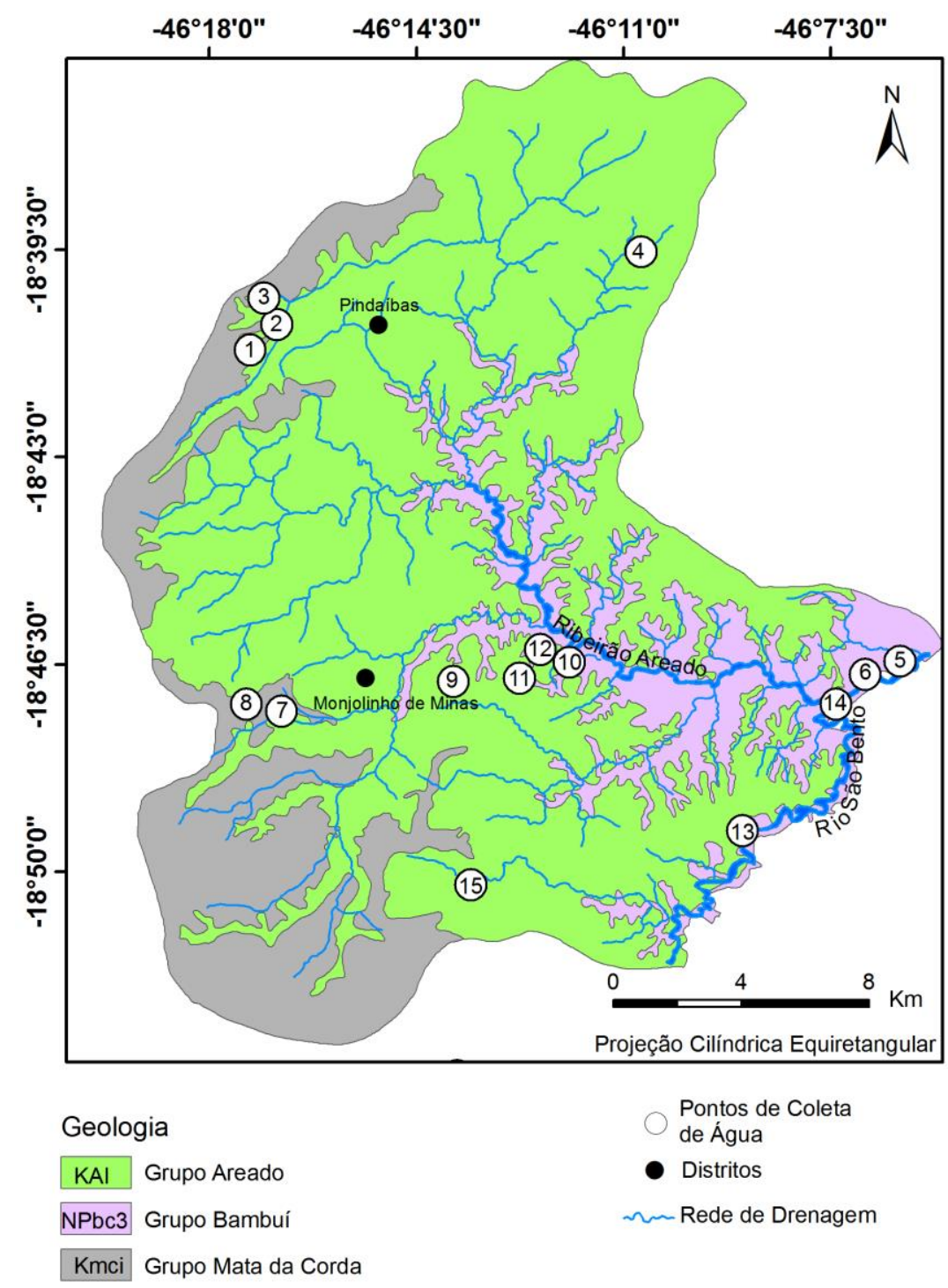

Elaboração: os autores.

O ponto 1 localizada a montante da criação de porcos (pocilga) e o ponto 2 a jusante logo após lançamento do esgoto da pocilga. Estes locais possuem relevo fortemente dissecado, com ocorrência de modo mais expressivo do afloramento de material tufítico e rochas associadas. O Latossolo Vermelho-Amarelo Distroférrico (LVdf) e o Cambissolo Háplico Tb Distrófico (CXbd) são os tipos de solos dominantes nas paisagens.

Os pontos 4, 9 e 15 encontram-se em superfície dissecada e com influencia de rochas do Grupo Areado e associadas. A hidrografia corresponde a leitos de córregos. Os solos dominantes são o Latossolo Vermelho-Amarelo Distrófico (LVAd) e Argissolo Vermelho-Amarelo Eutrófico (PVAe).

Os pontos 5, 6, 13 e 14 encontram-se em fundo de vales denominados de vales encaixados, sob influencia do material geológico de base, Grupo Bambuí e rochas associadas. A hidrografia corresponde a leitos de rios. O ponto 5 encontra-se a jusante do distrito Major Porto e o ponto 6 a montante do referido distrito. Os solos de ocorrência correspondem ao Cambissolo Háplico Tb Distrófico (CXbd) e ao Argissolo Vermelho-Amarelo Eutrófico (PVAe). 
Os pontos 10,11 e 12 encontram-se em superfície dissecada e vales encaixados, respectivamente. $O$ material geológico corresponde ao Grupo Bambuí e rochas associadas. Os solos de ocorrência correspondem ao Cambissolo Háplico Tb Distrófico (CXbd) e ao Argissolo Vermelho-Amarelo Eutrófico (PVAe). A hidrografia onde foram coletadas as amostras corresponde a córrego (pontos 10) e a nascentes (pontos 11 e 12).

Os resultados químicos discutidos a seguir refletiram uma situação momentânea da qualidade das águas dos pontos amostrados na região do Alto Francisco, correspondente a bacia hidrográfica do Ribeirão Areado. Ao comparar os resultados com as normas de qualidade da água para o consumo humano, estabelecidas pela portaria no. 1.469, de 29 de dezembro de 2000 e com os valores padrões físicos e químicos segundo os Critérios Recomendados pelo Conselho Nacional do Meio Ambiente (CONAMA), Resolução no 357, de 17 de março de 2005, a classe de enquadramento da bacia foi a 2, estabelecido pelo CONAMA.

\section{pH e condutividade elétrica}

Todas as amostras analisadas do período chuvoso apresentaram $\mathrm{pH}$ dentro da faixa de 6,5 a 8,5 (figura 3), considerada normal para águas de classe 2 de acordo com a legislação (BRASIL, 2005), que cita valores de $\mathrm{pH}$ ideal na faixa de 6 a 9. Apenas as amostras dos pontos de coletas 1 e 9 , localizados em córrego, do período seco foram obtidos valores de $\mathrm{pH}$ abaixo do estabelecido pela legislação, 5,63 e 5,65, respectivamente.

A consequência do $\mathrm{pH}$ baixo é que facilita a liberação dos metais da rocha e solo para a água (JAIN, 2004; GUILHERME et al., 2002). Segundo Castro (1980) e Singh et al., (2005), um pH menor que 6,0 ou maior que 9,0 indica a presença de algum poluente. Valores fora das faixas recomendadas podem alterar o sabor da água, contribuir para a corrosão do sistema de distribuição de água, elevar a solubilização e uma possível extração de elementos como ferro, cobre, chumbo e zinco, dificultando, assim, a descontaminação das águas (CETESB, 2001).

Os valores de $\mathrm{pH}$ encontrados neste estudo assemelham-se a outros realizados em áreas que apresentam uso parecidos, com intensa apropriação agropecuária próximo aos cursos de água (Azevedo, 1995; Fernandes, 1996; Campos, 1999; Ribeiro, 2002) ou, refletem, o material de origem sobre os quais formaram os solos ou é uma indicação do caráter ácido dos solos dominantes.

Figura 3: Valores de pH dos pontos de coleta de água no período seco e chuvoso.

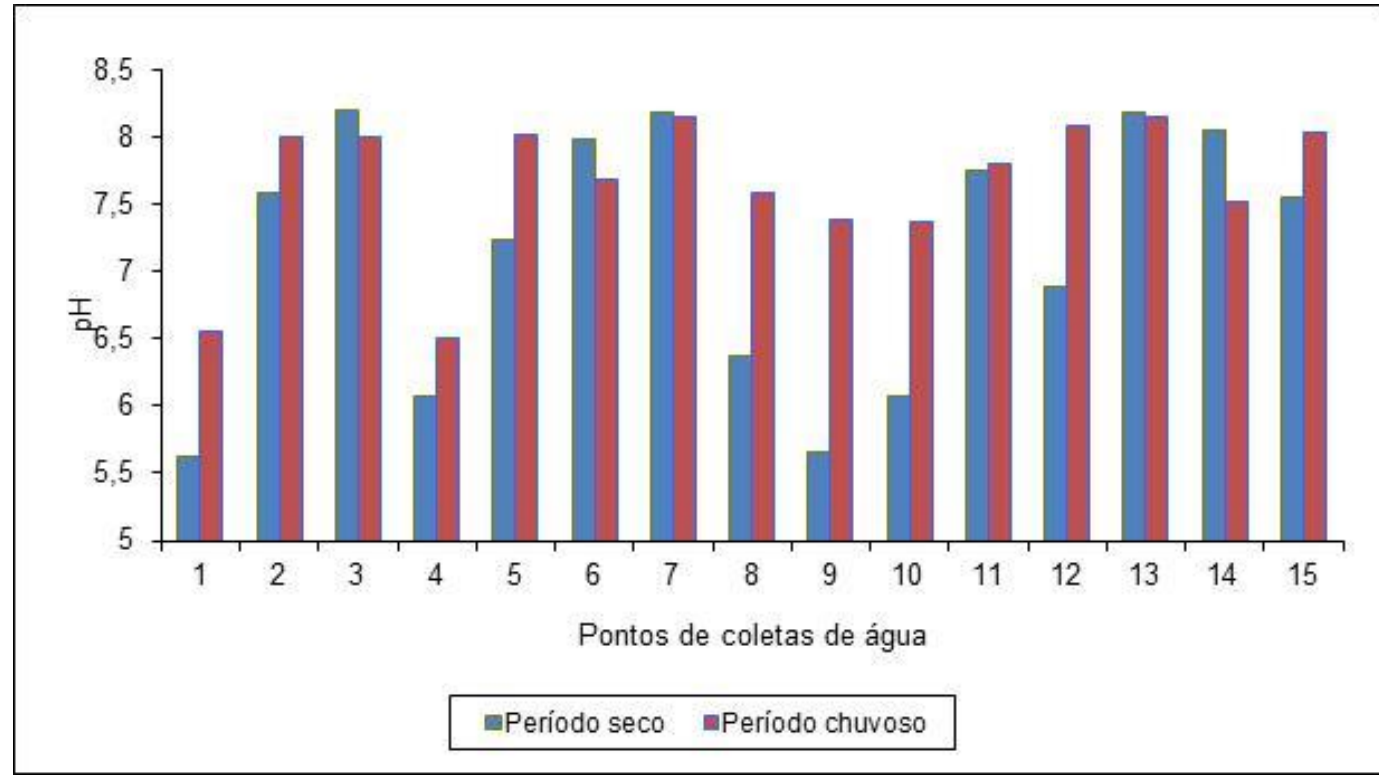

Fonte: Dados obtidos em trabalho de campo e em laboratório. 
Nesse sentido, no ponto 1 (córrego), há dominância de Latossolo com valores de pH ácido $(4,10 \mathrm{a}$ 4,70). Este solo tem influência de material tufito, mas se apresenta quimicamente altamente desaturado em razão da alta capacidade de intemperização e lixiviação do material de origem tufito. No ponto 9 (córrego) há dominância do Argissolo que, embora apresente com caráter eutrófico em subsuperfície, em superfície há ocorrência de $\mathrm{pH}$ moderadamente ácido $(5,94)$. Neste caso, demonstra a influência do uso intensivo deste solo com pastagens que resultou num desgaste químico levando superficialmente este solo a uma condição de desaturação das bases. Deve-se considerar, também, a ocorrência comum de erosão em sulco neste solo, cuja resultante é a perda das bases que são carreadas para os corpos d'água.

Os valores de condutividade elétrica (CE) em ambos os períodos, seca e chuva, refletem, naturalmente, a presença de substâncias iônica dissolvidas nas amostras de água analisada. Neste estudo os valores de condutividade elétrica foram inferiores $0,45 \mathrm{dS} \mathrm{m}^{-1}$ (Figura 4) para todos os pontos de coleta e ambos os períodos de seca e chuva. Portanto, os valores de condutividade elétrica nas águas da Bacia encontram-se nos padrões pré-estabelecido para uso em irrigação, sem restrição do seu uso para esta finalidade.

Os valores encontrados para a CE foram mais elevados no período seco que em relação ao período chuvoso (figura 4), exceção aos pontos de coletas 2 (córrego) e 3 (nascente) do período chuvoso que apresentaram valores mais elevados, 0,25 e $0,20 \mathrm{dS} \mathrm{m}^{-1}$, respectivamente. Estes maiores valores de CE nos pontos de coletas 2 e 3 refletem à riqueza química do local e a presença de um ambiente mais conservador. Nestes pontos de coleta, interfase dos compartimentos morfopedológicos I/II, há influencia de material tufítico mais expressivo no ponto 3 (nascente) e da criação de suínos no ponto 2 (córrego). Tais pontos estão posicionados topograficamente em sopé dos interflúvios das áreas dissecadas, o que demonstrou serem pontos mais conservadores e, consequentemente, com menor perda química. De modo geral, os valores encontrados demonstram que no período seco há um maior efeito de concentração de íons nos corpos de água e no período chuvoso um maior efeito de diluição.

Figura 4: Valores de CE dos pontos de coleta de água no período seco e chuvoso.

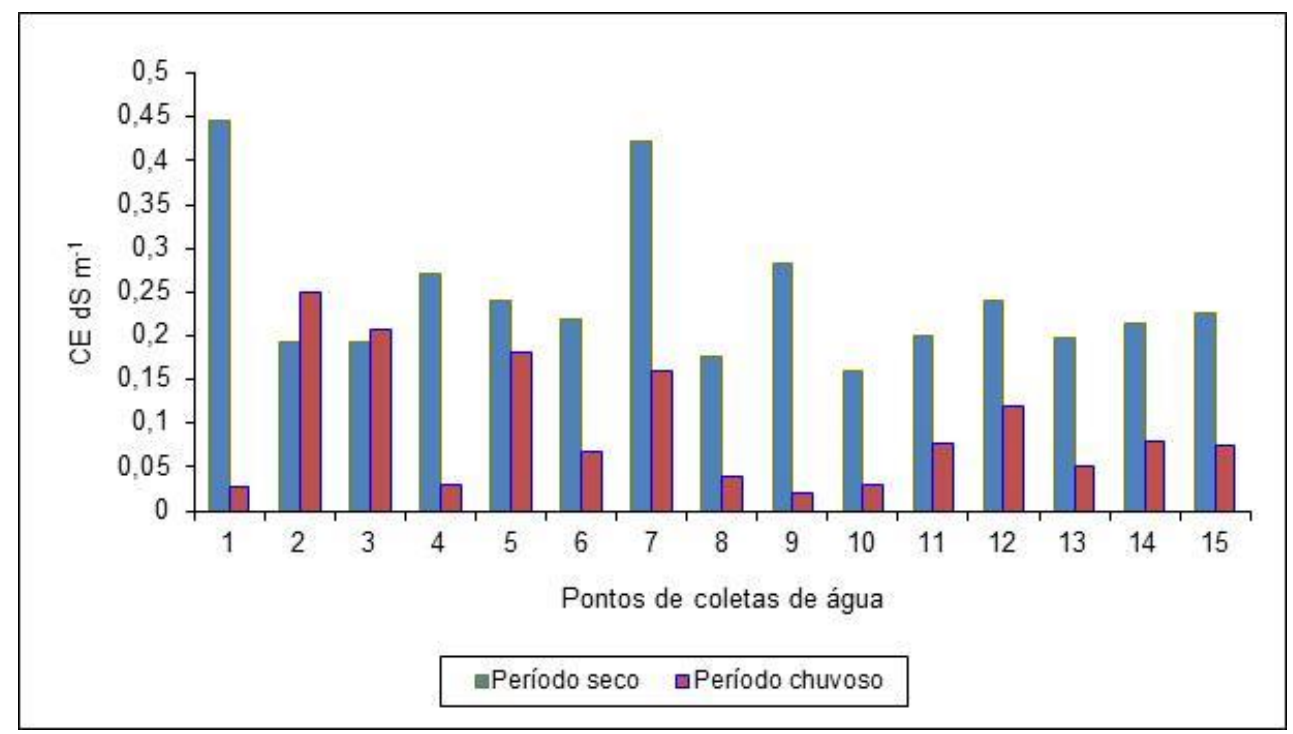

Fonte: Dados obtidos em trabalho de campo e em laboratório.

As concentrações de íons encontradas podem ser atribuídas, para os dois períodos de coleta, a ação humana, considerando que são áreas habitadas e a liberação destes pelos solos ou pelo substrato rochoso. De acordo com Santos (2000), a fonte principal e mais direta de todos os sais encontrados na água é a intemperização das rochas e a percolação da água no perfil do solo. Para este estudo, sobre a dominância de solos com textura argilosa e com boa porosidade total; infere-se que à medida que os íons são liberados da rocha matriz parte é retida na fração mineral do solo e a outra é lixiviada no perfil, como efeito há uma diminuição da concentração de íons que possam promover elevação da CE nos cursos d'água da Bacia.

$\begin{array}{llllll}\text { Caminhos de Geografia } & \text { Uberlândia - MG } & \text { v. 19, n. } 68 & \text { Dez/2018 } & \text { p. 81-115 } & \text { Página } 108\end{array}$


Os valores encontrados de condutividade elétrica para os dois períodos de coletas indicam baixa contribuição de íons para sua elevação nas amostras de água, provavelmente, devido ao efeito diluidor dos cursos d'água da Bacia. $\mathrm{E}$, indicam, de modo geral, corpos hídricos com alta capacidade de dispersão química destes elementos. Em síntese, a concentração de íons na água (CE) não influenciou espacialmente e nem temporalmente a disponibilidade qualitativa dos corpos hídricos na Bacia, o que a torna compatibilizada para as diversas atividades econômicas, o consumo humano e a proteção ambiental.

\section{Elementos químicos na água}

Há uma tendência, entre os quinze pontos de amostragem de água do período seco, de grande uniformidade nas concentrações dos elementos analisados, exceto para os elementos cálcio ( $\mathrm{Ca})$ e magnésio (Mg), cujo coeficiente de variação (CV) foi muito elevado (tabela 1).

Os coeficientes de variações dos pontos amostrados no período seco (tabela 1) tendem a ser mais elevados, comparativamente ao período chuvoso (tabela 2). É possível que o aparecimento de baixas concentrações médias no período chuvoso para a maioria dos elementos analisados, seja influenciado pela diluição provocada pelo aumento do volume de água dos cursos de água da Bacia. Facetti et al. (1998); Ali, et al. (1999); Cunha (2003) e Soares (2006) também encontraram variação sazonal na concentração de elementos químicos em águas superficiais, evidenciando um maior efeito de diluição dos elementos químicos nas águas em período de maior índice pluviométrico.

Tabela 1: Composição química das águas no período seco



Fonte: Dados obtidos em trabalho de campo e em laboratório.

Observa-se o efeito da diluição pelo aumento da percolação, especialmente nos valores de fósforo (P) que, por sua característica de menor mobilidade no solo, teve sua concentração diminuída no período chuvoso em relação ao período seco. Por outro lado, os elementos de maior mobilidade, especialmente sódio $(\mathrm{Na})$ e cálcio $(\mathrm{Ca})$ apresentaram um aumento de concentração nas águas de drenagem no período chuvoso, indicando uma elevada lixiviação destes elementos do solo para as águas de drenagem (tabelas 1 e 2).

Houve uma diminuição das médias das concentrações de cobalto (Co), chumbo (Pb), boro (B), vanádio $(\mathrm{V})$, cobre $(\mathrm{Cu})$, níquel $(\mathrm{Ni})$, cromo $(\mathrm{Cr})$, cadmo $(\mathrm{Cd})$, cálcio $(\mathrm{Ca})$, fósforo $(\mathrm{P})$, titânio $(\mathrm{Ti})$, magnésio (Mg) e manganês $(\mathrm{Mn})$ do período seco para o período chuvoso (Tabelas 1 e 2),

$\begin{array}{llllll}\text { Caminhos de Geografia } & \text { Uberlândia - MG } & \text { v. 19, n. 68 } & \text { Dez/2018 } & \text { p. 81-115 Página } 109\end{array}$


corroborando com o efeito de diluição. Para os elementos zinco $(\mathrm{Zn})$, ferro $(\mathrm{Fe})$, potássio $(\mathrm{K})$, alumínio (Al) e sódio (Na) a maior média é apresentada para o período chuvos.

As concentrações médias elevadas desses elementos no período chuvoso podem ser uma contribuição do material de origem tufito (Grupo Mata da Corda), que em sua composição apresenta esses elementos em altas concentrações.

Tabela 2: Composição química das águas no período chuvoso.

\begin{tabular}{|c|c|c|c|c|c|c|c|c|c|c|c|c|c|c|c|c|c|c|c|c|}
\hline \multirow[b]{3}{*}{ VPLB ${ }^{1}$} & & Co & Zn & $\mathbf{P b}$ & B & $\mathrm{v}$ & $\mathrm{Cu}$ & $\mathbf{N i}$ & $\mathrm{Cr}$ & Cd & Fe & $\mathrm{Ca}$ & K & $\mathbf{P}$ & $\pi$ & Mg & Mn & Al & $\mathrm{Na}$ & \multirow[t]{2}{*}{$\begin{array}{l}\text { Dureza } \\
\mathrm{CaCO}_{3}\end{array}$} \\
\hline & & & & & & & & & & & $g^{-1}$ & & & & & & & & & \\
\hline & & 0,05 & 0,18 & 0,01 & 0,75 & 0,1 & 0,009 & 0,025 & 0,05 & 0,001 & 0,3 & & & 0,025 & & & 0,1 & 0,1 & - & \\
\hline VPAP $^{2}$ & & 2,00 & 5,00 & 0,01 & 0,70 & - & - & - & 0,05 & 0,005 & 0,30 & & & - & & & 0,10 & 0,20 & 200 & \\
\hline Pontos & Local & & & & & & & & Médi & a de tre & $s$ repeti & çōes & & & & & & & & \\
\hline 1 & Cómego & 0,00 & 1,89 & 0,04 & 0,21 & 0,00 & 0,04 & 0,00 & 0,00 & 0,00 & 0,00 & 0,62 & 3,04 & 0,00 & 0,05 & 0,07 & 0,00 & 0,16 & 11,34 & 2 \\
\hline 2 & Cómego & 0,04 & 0,00 & 0,00 & 0,19 & 0,00 & 0,02 & 0,00 & 0,00 & 0,00 & 0,00 & 17,51 & 14,16 & 0,00 & 0,02 & 25,51 & 0,00 & 0,09 & 7,64 & 149 \\
\hline 3 & Nascerte & 0,00 & 0,17 & 0,00 & 0,32 & 0,00 & 0,01 & 0,00 & 0,00 & 0,00 & 0,00 & 13,67 & 17,20 & 0,00 & 0,00 & 19,97 & 0,00 & 0,08 & 12,08 & 116 \\
\hline 4 & Cómego & 0,00 & 0,81 & 0,00 & 0,27 & 0,00 & 0,01 & 0,00 & 0,00 & 0,00 & 0,98 & 0,74 & 1,27 & 0,00 & 0,01 & 0,65 & 0,00 & 0,43 & 1,73 & 5 \\
\hline 5 & Rio & 0,00 & 0,02 & 0,00 & 0,29 & 0,00 & 0,01 & 0,00 & 0,00 & 0,00 & 0,00 & 27,66 & 14,67 & 0,00 & 0,00 & 3,28 & 0,00 & 0,25 & 10,35 & 83 \\
\hline 6 & Rio & 0,00 & 4,94 & 0,00 & 0,41 & 0,00 & 0,02 & 0,00 & 0,00 & 0,00 & 11,23 & 6,29 & 35,91 & 0,00 & 0,40 & 6,08 & 0,00 & 7,55 & 20,46 & 41 \\
\hline 7 & Represa & 0,00 & 2,23 & 0,00 & 0,22 & 0,00 & 0,01 & 0,00 & 0,00 & 0,00 & 0,14 & 12,71 & 23,52 & 0,00 & 0,07 & 15,47 & 0,00 & 0,39 & 15,28 & 95 \\
\hline 8 & Nascerte & 0,00 & 0,87 & 0,00 & 0,25 & 0,00 & 0,02 & 0,00 & 0,00 & 0,00 & 0,78 & 1,11 & 11,38 & 0,00 & 0,00 & 1,18 & 0,00 & 0,09 & 8,63 & 8 \\
\hline 9 & Cómego & 0,00 & 0,00 & 0,00 & 0,38 & 0,00 & 0,00 & 0,00 & 0,00 & 0,00 & 0,00 & 2,23 & 3,29 & 0,00 & 0,00 & 2,04 & 0,00 & 0,10 & 5,92 & 14 \\
\hline 10 & Cómego & 0,00 & 0,01 & 0,21 & 0,25 & 0,00 & 0,00 & 0,00 & 0,00 & 0,00 & 0,02 & 1,11 & 6,33 & 0,00 & 0,00 & 0,95 & 0,00 & 0,07 & 7,64 & 7 \\
\hline 11 & Nascerte & 0,00 & 0,00 & 0,00 & 0,24 & 0,00 & 0,02 & 0,00 & 0,00 & 0,00 & 9,48 & 8,13 & 26,05 & 0,00 & 0,69 & 8,85 & 0,00 & 4,49 & 5,67 & 57 \\
\hline 12 & Nascerte & 0,00 & 0,00 & 0,00 & 0,30 & 0,00 & 0,00 & 0,00 & 0,00 & 0,00 & 0,01 & 9,64 & 18,21 & 0,00 & 0,02 & 12,71 & 0,00 & 0,43 & 7,15 & 76 \\
\hline 13 & Rio & 0,00 & 0,01 & 0,00 & 0,23 & 0,00 & 0,02 & 0,00 & 0,00 & 0,00 & 13,19 & 4,05 & 24,03 & 0,00 & 0,73 & 5,86 & 0,00 & 6,61 & 6,41 & 34 \\
\hline 14 & Rî́ & 0,00 & 0,01 & 0,00 & 0,22 & 0,00 & 0,01 & 0,00 & 0,00 & 0,00 & 7,67 & 5,27 & 26,05 & 0,00 & 0,12 & 4,69 & 0,00 & 6,23 & 17,25 & 32 \\
\hline 15 & Cómego & 0,00 & 0,01 & 0,00 & 0,29 & 0,00 & 0,00 & 0,00 & 0,00 & 0,00 & 1,01 & 7,77 & 9,87 & 0,00 & 0,01 & 3,46 & 0,00 & 0,77 & 12,08 & 34 \\
\hline Minimo & & 0,00 & 0,00 & 0,00 & 0,19 & 0,00 & 0,00 & 0,00 & 0,00 & 0,00 & 0,00 & 0,62 & 1,27 & 0,00 & 0,00 & 0,07 & 0,00 & 0,07 & 1,73 & \\
\hline Máxino & & 0,04 & 4,94 & 0,21 & 0,41 & 0,00 & 0,02 & 0,00 & 0,00 & 0,00 & 13,19 & 27,66 & 35,91 & 0,00 & 0,73 & 25,51 & 0,00 & 7,55 & 20,46 & \\
\hline Média & & 0,00 & 0,73 & 0,02 & 0,27 & 0,00 & 0,01 & 0,00 & 0,00 & 0,00 & 2,97 & 7,90 & 15,66 & 0,00 & 0,14 & 7,39 & 0,00 & 1,85 & 9,98 & \\
\hline C.V. (\%) & & 0,00 & 1,76 & 0,00 & 0,00 & 0,00 & 0,00 & 0,00 & 0,00 & 0,00 & 21,28 & 53,03 & 95,21 & 0,00 & 0,06 & 55,58 & 0,00 & 7,31 & 22,55 & \\
\hline
\end{tabular}

Fonte: Dados obtidos em trabalho de campo e em laboratório.

A influencia da variação litológica se expressa melhor no período seco (tabela 3) quando a diluição é pequena, notadamente para os elementos que caracterizam o material de origem tufítico, ou seja, magnésio $(\mathrm{Mg})$, fósforo $(\mathrm{P})$, níquel $(\mathrm{Ni})$, cromo $(\mathrm{Cr})$, sódio $(\mathrm{Na})$, potássio $(\mathrm{K})$ e cálcio $(\mathrm{Ca})$. Quase sempre, concentrações maiores estão associadas ao material de origem tufito (Grupo Mata da Corda) e as menores concentrações ao arenito (Grupo Areado e Grupo Bambuí). Esta influência do material de origem associado à água de percolação é corroborada pelos teores expressivos desses elementos constantes n. Observam-se concentrações elevadas de níquel $(\mathrm{Ni})$, magnésio $(\mathrm{Mg})$, cálcio $(\mathrm{Ca})$, fósforo $(\mathrm{P})$ e sódio $(\mathrm{Na})$.

Tabela 3: Composição química média das águas de drenagem em materiais areníticos e tufíticos no período seco e chuvoso, Alto Paranaíba - MG.

\begin{tabular}{|c|c|c|c|c|c|c|c|c|c|c|c|c|c|c|c|c|c|c|}
\hline & Co & $\mathrm{Zn}$ & $\mathrm{Pb}$ & $B$ & $\mathrm{~V}$ & $\mathrm{Cu}$ & $\mathrm{Ni}$ & $\mathrm{Cr}$ & $\mathrm{Cd}$ & $\mathrm{Fe}$ & $\mathrm{Ca}$ & $\mathrm{K}$ & $\mathrm{P}$ & $\mathrm{Ti}$ & $\mathrm{Mg}$ & $\mathrm{Mn}$ & $\mathrm{Al}$ & $\mathrm{Na}$ \\
\hline & \multicolumn{18}{|c|}{ Período Seco } \\
\hline Média (Arenito & 0,03 & 0,57 & 0,03 & 0,29 & 0,02 & 0,04 & 0,03 & 0,05 & 0,01 & 1,34 & 15,87 & 2,01 & 1,00 & 1,28 & 3,11 & 0,14 & 0,42 & 0,69 \\
\hline Média (Tufito) & 0,03 & 0,44 & 0,03 & 0,71 & 0,04 & 0,06 & 0,04 & $\begin{array}{r}0,09 \\
P\end{array}$ & $\begin{array}{l}0,01 \\
\text { eríodo }\end{array}$ & $\begin{array}{l}1,65 \\
\text { chuv }\end{array}$ & $\begin{array}{l}22,73 \\
\text { oso }\end{array}$ & 1,89 & 1,11 & 1,31 & 16,61 & 0,35 & 0,48 & 1,05 \\
\hline Média (Arenito & 0,00 & 1,17 & 0,00 & 0,25 & 0,00 & 0,01 & 0,00 & 0,00 & 0,00 & 4,49 & 6,85 & 17,7 & 0,00 & 0,17 & 3,93 & 0,00 & 3,08 & 11,77 \\
\hline Média (Tufito) & 0,00 & 0,41 & 0,02 & 0,26 & 0,00 & 0,01 & 0,00 & 0,00 & 0,00 & 1,83 & 7,78 & 14,39 & 0,00 & 0,15 & 10,07 & 0,00 & 0,93 & 8,14 \\
\hline
\end{tabular}

Fonte: Dados obtidos em trabalho de campo e em laboratório.

A dureza depende, em grande parte, do solo a qual a água drena. Assim, águas moles são frequentemente encontradas em solos de natureza arenítica e máfica, enquanto águas provenientes de solos calcários apresentam frequentemente, durezas elevadas (BACAN, et. al., 1995). Dentre

$\begin{array}{llllll}\text { Caminhos de Geografia } & \text { Uberlândia - MG } & \text { v. 19, n. 68 } & \text { Dez/2018 } & \text { p. 81-115 } & \text { Página } 110\end{array}$


solos de natureza arenítica e máfica, há uma tendência de solos de natureza máfica apresentar águas de dureza mais elevada, em razão do conteúdo elevado de cálcio e magnésio na estrutura mineral da rocha de origem (SZABÓ et. al., 2001).

As maiores concentrações dos elementos cálcio $(\mathrm{Ca})$ e magnésio $(\mathrm{Mg})$ conferiram maior efeito na dureza das águas no período seco que em relação ao período chuvoso. No período seco a dureza é classificada como mole (até $50 \mathrm{mg} \mathrm{L}^{-1}$ de $\mathrm{CaCO}_{3}$ ) a dura $\left(150\right.$ a $300 \mathrm{mg} \mathrm{L}^{-1}$ de $\left.\mathrm{CaCO}_{3}\right)$ e no período chuvoso de mole a moderadamente mole $\left(50\right.$ a $150 \mathrm{mg} \mathrm{L}^{-1}$ de $\mathrm{CaCO}_{3}$ ) (tabela 1 e 2). Há uma tendência de maiores teores de $\mathrm{Ca}$ e $\mathrm{Mg}$ no material tufito, corroborando a maior dureza nas águas que drenam o tufito que em relação as águas que drenam o arenito (tabela 3).

Segundo Macêdo (1995), quando o pH da água encontra-se entre 4,4 e 8,4 a sua alcalinidade é determinada apenas por íons bicarbonatos, sendo impossível a coexistência de bicarbonatos e carbonatos na mesma amostra. Assim, a dureza das amostras de águas de todos os pontos analisados classifica-se como temporária em função do $\mathrm{pH}$ das mesmas, pois este tipo de dureza ocorre devido à presença de sais de cálcio e magnésio na forma de bicarbonatos.

\section{Concentração de elementos químicos no material em suspensão}

As concentrações de metais analisados no material em suspensão, provenientes dos 15 pontos de amostragem, encontram-se apresentados na tabela 4. Os dados analisados referem-se apenas ao período chuvoso pela razão da maior disponibilidade de sedimentos para análise. Observando-se os valores médios de concentração de elementos no material em suspensão (tabela 4), verifica-se que praticamente todos os pontos de coleta apresentaram teores significativos e variáveis de elementos químicos.

Os sedimentos em suspensão são considerados de grande importância na avaliação do nível de contaminação dos ecossistemas aquáticos, devido não só a sua capacidade em acumular elementos traço, mas também, por serem reconhecidos como transportadores e possíveis fontes de contaminação (OLIVEIRA e MARINS, 2011).

Tabela 4: Concentração de metais no material em suspensão em amostras de água coletada em período chuvoso

\begin{tabular}{|c|c|c|c|c|c|c|c|c|c|c|c|c|c|c|c|c|c|}
\hline $\begin{array}{l}\text { Pontos de } \\
\text { coletas }\end{array}$ & Co & $\mathrm{Zn}$ & $\mathrm{Pb}$ & $B$ & V & $\mathrm{Cu}$ & $\mathrm{Ni}$ & $\mathrm{Cr}$ & $\mathrm{Cd}$ & $\mathrm{Fe}$ & $\mathrm{Ca}$ & $\mathrm{K}$ & $P$ & $\mathrm{Ti}$ & $\mathrm{Mg}$ & $\mathrm{Mn}$ & $\overline{\mathrm{Al}}$ \\
\hline & & & & & & & & & & $\mathrm{mg} \mathrm{Kg}^{\prime}$ & & & & & & & \\
\hline $\mathrm{VN}^{1}$ & -- & 60 & 17 & -- & -- & 35 & 13 & 40 & 0,5 & -- & -- & -- & -- & -- & -- & -- & -- \\
\hline $\mathrm{MM}^{2}$ & -- & 350 & 150 & -- & -- & 100 & -- & 100 & - & -- & -- & -- & -- & -- & -- & -- & -- \\
\hline 1 & nd & 0,32 & 0,06 & 364,06 & nd & 0,06 & nd & nd & nd & 109,47 & 35,23 & 4,97 & 19,75 & 2,35 & 9,98 & nd & 218,77 \\
\hline 2 & 0,06 & 0,20 & 0,02 & 138,12 & 0,25 & 0,21 & 0,30 & 0,22 & nd & 181,90 & 15,15 & 12,18 & 22,19 & nd & 8,35 & 1,88 & 98,57 \\
\hline 3 & 0,13 & 0,21 & 0,04 & 164,62 & 0,40 & 0,31 & 0,41 & 0,39 & nd & 39,25 & 26,74 & 2,24 & 25,22 & 9,00 & 6,55 & 2,45 & 113,08 \\
\hline 5 & nd & 0,26 & nd & 243,97 & nd & 0,06 & nd & nd & nd & 123,09 & 55,40 & 10,28 & 23,05 & 5,20 & 13,44 & 0,11 & 185,09 \\
\hline 6 & 3,08 & 0,99 & 19,80 & 0,45 & 1112,08 & 18,76 & 7,07 & 6,66 & 8,25 & 5210,71 & 9804,38 & 393,20 & 323,06 & 364,40 & 77,51 & 130,13 & 619,89 \\
\hline 7 & 35,06 & nd & 15,42 & 3,36 & 5955,93 & 132,24 & 64,53 & 63,01 & 70,00 & 4739,56 & 327,18 & 3485,30 & 439,38 & 494,42 & 90,04 & 214,08 & 830,41 \\
\hline 8 & 1,88 & 2,04 & 0,53 & 372,15 & 4,92 & 3,41 & 4,11 & 2,78 & nd & 380,83 & 109,87 & 14,90 & 254,88 & 83,90 & 37,63 & 26,82 & 973,78 \\
\hline 9 & nd & nd & nd & 518,60 & nd & 0,20 & nd & nd & nd & 235,08 & 33,19 & 10,40 & 40,16 & 2,59 & 9,91 & nd & 202,94 \\
\hline 10 & nd & nd & 0,41 & nd & 2569,83 & nd & 0,59 & nd & nd & nd & 234,19 & 31,70 & 47,64 & 53,78 & 7,14 & 12,14 & nd \\
\hline 11 & nd & 0,08 & 0,02 & 574,51 & nd & 0,03 & nd & nd & nd & 89,85 & 15,29 & 13,24 & 11,90 & 2,70 & 3,53 & nd & 214,95 \\
\hline 12 & 5,95 & 0,23 & 1,23 & 483,05 & 680,54 & 21,80 & 15,96 & 18,68 & 11,01 & 1615,90 & 1912,17 & 397,45 & 879,50 & 121,84 & 42,02 & 48,15 & 348,76 \\
\hline 13 & nd & 0,17 & 0,09 & 369,49 & 0,12 & 0,21 & 0,10 & 0,05 & nd & 131,49 & 54,61 & 9,41 & 19,38 & 17,41 & 13,94 & 1,55 & 225,32 \\
\hline 14 & 212,58 & 380,62 & 139,65 & 13411,22 & 1145,62 & 636,18 & 992,01 & 962,42 & 99,62 & nd & 71322,16 & 9816,24 & 41991,66 & 4750,91 & 20653,80 & 4193,99 & 19240,06 \\
\hline 15 & 34,69 & nd & 2,80 & 3008,03 & 2932,99 & 97,40 & 59,27 & 68,63 & 63,94 & 4527,46 & 9433,46 & 3340,79 & 3424,32 & 3626,22 & 112,60 & 733,40 & 430,49 \\
\hline 16 & 8,60 & 17,49 & 11,80 & 2453,11 & 42,95 & 12,98 & 12,46 & 23,43 & nd & 4266,51 & 124,70 & 294,06 & 590,48 & nd & 29,86 & 164,73 & 739,77 \\
\hline 17 & 7,08 & 11,68 & 8,24 & 9490,92 & 9,70 & 11,56 & 14,07 & 15,01 & nd & 3105,58 & 291,75 & 235,98 & 756,59 & 378,76 & 71,96 & 106,83 & 4850,24 \\
\hline 19 & 0,56 & 1,40 & 0,44 & 321,84 & 2,92 & 1,45 & 1,17 & 1,80 & nd & 236,32 & 32,00 & 22,89 & 97,37 & 36,49 & 11,01 & 14,62 & 1330,03 \\
\hline 20 & 0,74 & nd & 0,19 & 178,84 & 1135,85 & 2,48 & 1,35 & 1,54 & 1,72 & nd & 234,65 & 19,85 & 88,79 & 95,77 & 39,50 & 6,20 & nd \\
\hline 21 & nd & nd & 0,61 & 0,25 & 1297,51 & 0,23 & 0,21 & 0,02 & 0,09 & nd & 193,62 & 215,66 & 30,84 & 35,00 & 18,48 & 53,19 & nd \\
\hline 22 & nd & 2,00 & nd & 349,02 & nd & 0,16 & nd & nd & nd & 142,17 & 22,36 & 7,15 & 27,15 & 4,75 & 4,27 & nd & 176,50 \\
\hline Mínimo & 0,06 & 0,08 & 0,02 & 0,25 & 0,12 & 0,03 & 0,10 & 0,02 & 0,09 & 39,25 & 15,15 & 2,24 & 11,90 & 2,35 & 3,53 & 0,11 & 98,57 \\
\hline Máximo & 212,58 & 380,62 & 139,65 & 13411,22 & 5955,93 & 636,18 & 992,01 & 962,42 & 99,62 & 5210,71 & 71322,16 & 9816,24 & 41991,66 & 4750,91 & 20653,80 & 4193,99 & 19240,06 \\
\hline Média & 25,87 & 29,84 & 11,84 & 1707,66 & 1126,11 & 49,46 & 78,24 & 83,19 & 36,38 & 1570,95 & 4713,91 & 916,89 & 2455,67 & 560,31 & 1063,08 & 356,89 & 1811,69 \\
\hline
\end{tabular}

Fonte: Dados obtidos em trabalho de campoe em laboratório.

Neste caso, os dados médios mostram que para este estudo, o transporte de metais no material em suspensão nas águas de drenagem da Bacia não faz distinção quanto ao tamanho do curso de água. Ou seja, independentemente do tamanho do curso de água analisado, os teores de metais no 
material em suspensão parecem indicar uma importância significativa, contudo os valores determinados não refletem a disponibilidade desses elementos.

Ao analisar os teores dos elementos contidos no material em suspensão e correlacionando com os valores normais $(\mathrm{VN})$ e a média mundial $(\mathrm{MM})$ tem-se que, para os elementos cobre $(\mathrm{Cu})$, níquel $(\mathrm{Ni})$ e Cadmo (Cd) os valores apresentam-se acima dos valores normais para solos não contaminados, ou seja, acima de $35 \mathrm{mg} \mathrm{kg}^{-1}, 13 \mathrm{mg} \mathrm{kg}^{-1}$ e $0,5 \mathrm{mg} \mathrm{kg}^{-1}$, respectivamente. Apenas o cromo apresenta-se com valores acima dos considerados normais e acima da média mundial para material em suspensão. Segundo SINGH e STEINNES (1994), os metais em solos são derivados tanto do intemperismo, que age sobre o material parental, como de fontes externas naturais (erupção vulcânica) ou antrópicas (indústrias, agricultura).

Ao considerar os dados de modo pontual, verifica-se que as amostras de água coletadas nos pontos 12 (nascente) e 13 (rio), presentes na interface dos compartimentos morfopedológico II/III encontramse acima da média mundial para material em suspensão para os elementos zinco $(\mathrm{Zn})$, chumbo $(\mathrm{Pb})$, cobre $(\mathrm{Cu})$ e cromo ( $\mathrm{Cr})$ (Martin \& Meybeck, 1979) e os pontos 10 (córrego), 12 (nascente) e 13 (rio), presentes na interface dos compartimentos morfopedológico II/III, e o ponto 5 (rio) presente no compartimento III a jusante do distrito Major Porto, apresentam-se acima do valor normal para solos não contaminados para zinco $(\mathrm{Zn})$, chumbo $(\mathrm{Pb})$, cobre $(\mathrm{Cu})$, níquel $(\mathrm{Ni})$, cromo $(\mathrm{Cr})$ e Cadmo $(\mathrm{Cd})$ (tabela 4). Os demais elementos, cobalto $(\mathrm{Co})$, bário $(\mathrm{B})$, vanádio $(\mathrm{V})$, ferro $(\mathrm{Fe})$, cálcio $(\mathrm{Ca})$, potássio $(\mathrm{K})$, fósforo $(\mathrm{P})$, titânio $(\mathrm{Ti})$, manganês $(\mathrm{Mn})$, magnésio $(\mathrm{Mg})$ e alumínio $(\mathrm{Al})$ apresentam-se com teores disponíveis condizentes com a influência de sedimentos oriundos dos litotipos presentes na bacia e tipologias de solos que foram transportados pela rede de drenagem da Bacia.

Os dados corroboram com a riqueza química do tufito em elementos químicos e com a natureza pedogenética dos solos. Paisagens com solos pouco desenvolvidos como os Neossolos, Cambissolos e Argissolos acumulam mais bases e, paisagens, com solos mais desenvolvidos, como os Latossolos, tendem acumular-se menos bases e mais ferro, alumínio e titânio.

As elevadas concentrações de metais no material em suspensão refletem, provavelmente, ao maior volume de água desses cursos de água na ocasião das coletas, período chuvoso. Segundo KabataPendias e Pendias (2001), alta proporção de elementos químicos na forma particulada é típica de cursos de água que estão sujeitos a altas cargas de turbidez, típica de período chuvoso. Neste estudo, reflete, também, o efeito concentrador/receptor da porção jusante dos fluxos de água, que no presente estudo corresponde à porção de inserção da interfase dos compartimentos morfopedológicos II/III e o compartimento morfopedológico III.

Alguns exemplos na literatura relatam a importância do material em suspensão como agente transportador de elementos traços entre as unidades de paisagens e, permite extrapolar estes dados como um prognóstico do potencial de contaminação do meio. O trabalho de Gibbs (1977) realizado no Rio Amazonas e no Rio Yokon (Alaska), relata que o material em suspensão pode transportar de 65 a $92 \%$ de cromo, manganês, ferro, cobalto, níquel e cobre. Concentrações elevadas de cromo, entre 41 a $3400 \mathrm{mg} \mathrm{kg}^{-1}$, foram encontradas no material em suspensão na foz do Rio Besós e nas tubulações da estação de tratamento de águas residuárias de Barcelona, Espanha (PALANQUES, 1994). Em rios da costa leste dos EUA, Windom et al. (1991) encontraram elementos químicos ligados a partículas sólidas na proporção de $62 \%$ para cadmo, $40 \%$ para cobre, $90 \%$ para chumbo e $80 \%$ para zinco.

Estes trabalhos corroboram com o presente estudo e, indicam, que há uma significativa fração total de elementos químicos nos cursos de água que encontra-se preferencialmente na fração não dissolvida, mas adsorvida à superfície de partículas sólidas em suspensão, o que parece que o transporte de metais em solução é de secundária importância. Ao mesmo tempo, a alta variabilidade nos teores de elementos químicos nestes sedimentos em suspensão mostra que não só a matriz mineral, como também os processos intempéricos, pedogenéticos e suas complexas relações com as atividades econômicas podem interferir na composição dos elementos na água de drenagem da Bacia.

\section{Análise espacial da qualidade das águas}

Os comportamentos dos parâmetros químicos de qualidade das águas para os pontos amostrados ao longo dos cursos de água examinados foram avaliados e tiveram como referência os padrões de qualidade da Resolução CONAMA no 357 de 17/03/2005, para águas de classe 2 e os padrões de

$\begin{array}{llllll}\text { Caminhos de Geografia } & \text { Uberlândia - MG } & \text { v. 19, n. 68 } & \text { Dez/2018 } & \text { p. 81-115 } & \text { Página } 112\end{array}$


Potabilidade da portaria №. 1.469 de 29/12/2000.

$\mathrm{Na}$ análise, consideraram-se apenas os elementos que se apresentaram em desacordo com a legislação. No período seco os elementos químicos zinco $(\mathrm{Zn})$, chumbo $(\mathrm{Pb})$, cobre $(\mathrm{Cu})$, níquel $(\mathrm{Ni})$, cromo $(\mathrm{Cr})$, ferro $(\mathrm{Fe})$, fósforo $(\mathrm{P})$, manganês $(\mathrm{Mn})$ e alumínio $(\mathrm{Al})$, apresentaram concentrações médias acima dos limites para serem enquadrados como de classe 2, conforme a Resolução CONAMA no 357 de 17/03/2005. No período chuvoso os elementos zinco (Zn), chumbo (Pb), cobre $(\mathrm{Cu})$, ferro $(\mathrm{Fe})$ e alumínio $(\mathrm{Al})$ apresentaram com concentração média acima da referida legislação (Tabelas 1 e 2).

Quanto ao padrão de potabilidade observa-se que as águas da região apresentam-se fora dos padrões estabelecidos pela legislação. No período seco destacam-se os elementos cadmo (Cd), cromo $(\mathrm{Cr})$, chumbo $(\mathrm{Pb})$, ferro $(\mathrm{Fe})$, alumínio $(\mathrm{Al})$ e manganês $(\mathrm{Mn})$ e no período chuvoso os elementos chumbo $(\mathrm{Pb})$, ferro $(\mathrm{Fe})$ e alumínio $(\mathrm{Al})$ com concentrações médias acima dos valores permitidos pela portaria ํo. 1.469 de 29/12/2000 (Tabelas 1 e 2). A análise espacial do parâmetro químico de qualidade das águas permitiu identificar os pontos mais críticos, isto é, onde a qualidade encontra-se significativamente comprometida. A qualidade química das águas da Bacia torna-se mais crítica nos pontos situados nas partes dissecadas do relevo, interface dos compartimentos morfopedológicos I e II, denominadas de superfície de aplainamento tabular e superfície dissecada, respectivamente, locais com influência mais direta do material tufito.

Outros pontos críticos são os locais de intensa apropriação econômica, sobretudo nas áreas adjacentes aos cursos de água em que há a criação de suínos e a intensa utilização agrícola com práticas desprovidas de técnicas de manejo e uso adequado do solo, além de utilização indiscriminadas de fertilizantes e agrotóxicos. Os demais pontos apresentam-se em áreas com baixa contribuição de elementos químicos ou sofre efeito maior da diluição, não sendo, portanto, detectável pelo método analisado.

Sendo assim, se um único elemento químico estiver fora do parâmetro estabelecido pela legislação, a qualidade dos cursos de água será considerada comprometida. Neste caso, os dados devem ser analisados considerando o número de amostragens e, principalmente, a sazonalidade das coletas. $\mathrm{Na}$ prática os dados mostram que há necessidade de um monitoramento sistemático da qualidade química das águas da Bacia no que se refere ao conteúdo de elementos traços, os quais apontam uma ameaça potencial à biodiversidade bem como aos ecossistemas e a saúde pública.

\section{CONSIDERAÇÕES FINAIS}

Há uma afinidade entre os elementos químicos (essenciais e tóxicos) e materiais de origem, a evidência é que a rocha de origem tufito é a que mais contribui e influênciou no conteúdo destes elementos químicos na água. Os materiais de origem dos solos, principalmente o tufito, contribuem a composição química das águas de drenagem, notadamente para os elementos químicos $\mathrm{Mg}, \mathrm{Ca}, \mathrm{P}$, $\mathrm{Ni}$ e Cr.

A diluição promovida pelas chuvas reduz sobremaneira os sinais de influência dos materiais litológicos sobre a composição química das águas de drenagem. Há uma maior concentração de elementos traços no período seco do ano. Os sedimentos coletados mostraram-se importantes acumuladores de elementos traços. As condições ambientais favorecem a ocorrência de formas precipitadas associadas ao sedimento. As concentrações dos elementos traços encontradas nas águas de drenagem refletiram a contribuição de origem natural, associada à geologia local, bem como a contribuição do uso do entorno pela agropecuária.

Os valores dos elementos cadmo $(\mathrm{Cd})$, cromo $(\mathrm{Cr})$, chumbo $(\mathrm{Pb})$, ferro $(\mathrm{Fe})$, alumínio $(\mathrm{Al})$, manganês $(\mathrm{Mn})$ e chumbo $(\mathrm{Pb})$ encontrados estão acima dos limites médios estabelecidos pela legislação



Os resultados apontam para necessidade do monitoramento da qualidade da água quanto ao conteúdo de alguns elementos químicos (zinco - Zn, chumbo - $\mathrm{Pb}$, cobre - $\mathrm{Cu}$, níquel - $\mathrm{Ni}$, cromo - $\mathrm{Cr}$, ferro - $\mathrm{Fe}$, fósforo - $\mathrm{P}$, manganês - Mn e alumínio - Al), a fim de controlar os valores reais com os valores estabelecidos pela Resolução CONAMA no 357 de 17/03/2005, visando a segurança de seu consumo pela população.

Por fim, a população residente na Bacia deve ficar atenta às consequências da bioacumulação de alguns elementos traços no organismo que podem gerar efeitos danosos à saúde, como exemplo, o

$\begin{array}{llllll}\text { Caminhos de Geografia } & \text { Uberlândia - MG } & \text { v. 19, n. 68 } & \text { Dez/2018 } & \text { p. 81-115 } & \text { Página } 113\end{array}$


excesso de cromo pode calçar câncer. Portanto, recomenda-se a realização periódica de exames de saúde a fim de minimizar os efeitos danosos.

\section{REFERÊNCIAS BIBLIOGRÁFICAS}

ALI, M. B.; TRIPATHI, R. D.; RAI, U. N.; PAL, A.; SINGH, S. P. Physico-chemical characteristics and pollution level of Lake Nanital (UP, Índia): role of macrophytes and phytoplankton in biomonitoring and phytoremediation of toxic metal ions. Chemos. p2171-2182, 1999.

APHA - AMERICAN PUBLIC HEALTH ASSOCIATION. Standard methods for the examination of water and wastewater, 20. ed., v. 1. Washington: APHA, AWWA, WEF, 1998. Paginação irregular.

AZEVEDO NETTO, J. M. Técnicas de abastecimento e tratamento de água. $2^{2}$ Ed, São Paulo: CETESB/ASCETESB, 549p. 1987.

AZEVEDO, E. M. Vazão e características físicas e químicas do deflúvio de microbacias hidrográficas cobertas com mata nativa, pastagem e eucaliptus grandis. Viçosa, Universidade Federal de Viçosa, 92p. 1995. (Tese Mestrado).

BRASIL. Conselho Nacional do Meio Ambiente - CONAMA. Resolução no 357 de 2005. Classificação das águas, doces, salobras e salinas do Território Nacional. Disponível em htpp/www.lapes.ufrgs.br. Acesso em 27 de abril de 2007.

BRASIL. Ministério da Saúde. Portaria oㅜ 1.469, de 29 de dezembro de 2000. Normas de qualidade da água para o consumo humano. Diário Oficial da Republica Federativa do Brasil, Brasília, № 14E, Seção 1, 2000.

BRASIL. Resolução no. 274. Dispõe sobre os parâmetros de qualidade da água para balneabilidade e dá outras providências. Diário Oficial da União de 28 de novembro de 2000.

BRASIL. Resolução no. 357. Dispõe sobre a classificação dos corpos de água e diretrizes ambientais para o seu enquadramento, bem como estabelece as condições e padrões de lançamento de efluentes, e dá outras providências. Diário Oficial da União de 18 de março de 2005.

CAMPOS, C. E. B. Indicadores de campo para solos hidromórficos do planalto de Viçosa, Minas Gerais. Viçosa, Universidade Federal de Viçosa, 123p. 1999. (Tese de Mestrado).

CASTRO, P. S. Influência da cobertura florestal na qualidade da água em duas bacias hidrográficas na região de Viçosa, MG. Piracicaba, Escola Superior de Agricultura Luiz de Queiroz, 107p. 1980. (Tese Mestrado).

CETESB - Companhia de Tecnologia e Saneamento Ambiental. Dados de perfil sanitário. São Paulo. Disponível em http:/www.cetesb.com.br. Acesso em 27 de outubro de 2012.

COTTA, J. A. O.; REZENDE, M. O. O.; PIOVANI, M. R. Avaliação do teor de metais em sedimento do rio Betari no parque estadual turístico do Alto Ribeira - PETAR, São Paulo. Química Nova, Vol. 29, №. 1, p40-45. 2006. https://doi.org/10.1590/S0100-40422006000100009

CUNHA, A. M. Ambientes, solo e uso com vista ao potencial de produção de água em microbacias (Mata Atlântica) do município de Guarapari, ES. Viçosa, Universidade Federal de Viçosa. 133p. 2003. (Tese de Mestrado).

FACETTI, J.; DEKOV, V. M.; VAN GRIEKEN, R. Heavy metals in sediments from the Paraguay River: a preliminary study. Sci. Total Env., 209-78-86, 1998.

FERNANDES, M. M. Caracterização de solos e uso atual empregando aerofotos nãoconvencionais nas sub-bacias Marengo, Palmital e Silibar-Turvo Sujo, MG. Viçosa, Universidade Federal de Viçosa, 107p. 1996. (Tese de Mestrado).

GUILHERME, L. R. G.; MARQUES, J. J.; PIERANGELE, M. P; ZULIANI, D, Q.; CAMPOS, M. Elementos traços em solos, sedimentos e água. In: V Smpósio Nacional sobre Recuperação de áreas degradadas. Belo Horizonte, 2002, Anais. Belo Horizonte, 2002.

JAIN, C. K. Metal fractionation study on bed sedments of river Yamuna, Índia. Water Res., 38:569578, 2004. https://doi.org/10.1016/j.watres.2003.10.042 
KABATA-PENDIAS, A.; PENDIAS, H. Traces elements in soils and plants. $3^{2}$ ed. Boca Raton, CRC Press. 413p. 2001.

MACÊDO, J. A. B. Sistema especialista para controle e tratamento de água na indústria de alimentos. Tese de Mestrado, Departamento de Ciências e Tecnologia de Alimentos, Universidade Federal de Viçosa, Viçosa, Minas Gerais. 93p. 1995.

MARTIN, J. M.; MEYBECK, M. Elemental mass-balance of material carried by major world rivers. Mar. Chemical. p173-206, 1979. https://doi.org/10.1016/0304-4203(79)90039-2

MOZETO, A. A. Manejo da qualidade da água e da dinâmica do sedimento e do particulado da represa do Guarapiranga e do rio Grande, RMSP, UFSCAR: São Carlos, 1996. (Projeto RHAE, processo n0610419/95-1).

NASCIMENTO, F. R.; CUNHA, S. B. Classes de solos e unidades morfo-pedológicas na bacia hidrográfica do rio Acaraú - Ceará. VI Simpósio Nacional de Geomorfologia. Geomorfologia tropical e subtropical: processos, métodos e técnicas. Goiás/Brasil, Goiânia-GO. Setembro. 11p. 2006.

OLIVEIRA, R. C. B; MARINS, R. V. Dinâmica de metais-traço em solo e ambiente sedimentar estuarino como um fator determinante no aporte desses contaminantes para o ambiente aquático: revisão. Revista Virtual Química, vol. 3, № 2, p88-102. 2011

RIBEIRO, P. R. S. Caracterização química, física e microbiológica de cursos d'água da bacia do rio Turvo Limpo. Viçosa, Universidade Federal de Viçosa. 181p. 2002. (Tese de Mestrado).

ROSS, J. L. S.; DEL PRETTE, M. E. Recursos hídricos e as bacias hidrográficas: âncoras do planejamento e gestão ambiental. Revista do departamento de Geografia. ํㅡㄴ 12. 1998 .

SANTOS, J. G. R. A salinidade na agricultura irrigada: teoria e prática. Campina Grande: UFPB, 171p. 2000.

SINGH, P. K.; MOHAN, D.; SINGH, V. K.; MALIK, A. Studies on distribution and fractionation of heavy metals in Gomti river sediments a tributary of the Ganges, India. J. Hydrol. 312:14-27, 2005. https://doi.org/10.1016/i.jhydrol.2005.01.021

SOARES, C. R. A. Concentração de metais pesados em sedimentos, água e macrófitas aquáticas em duas represas do Município de Viçosa - MG. Viçosa, Universidade Federal de Viçosa, 186p. 2006. (Tese de Doutorado).

TUNDISI, J. G.; MATSUMURA-TUNDISI, T. Recursos hídricos no século XXI. São Paulo: Oficina de Textos. 388p. 2011.

VALENTE, O. F.; CASTRO, P. S. Manejo de bacias hidrográficas. Informe agropecuário, Belo Horizonte, no 80, v. 7, ago. p.40-45. 1981.

Recebido em: 26/10/2017

Aceito para publicação em: 03/09/2018 